\title{
Twitter, public engagement and the Eurocrisis: More than an echo
}

\section{chamber?}

Asimina Michailidou

\section{Introduction}

Digital media have ushered in a new era in crisis communication by restraining the control of traditional journalistic media and political leaderships over information flows on the one hand, and strengthening the informational and participatory independence of the public, on the other. In this sense, online media have opened up an asymmetric public arena for crisis communication, within which it is increasingly difficult for formal political institutions to claim or maintain their reputation and trustworthiness. At the same time, this online public arena that mediates crisis communication has the potential to foster political innovation because it enables the formation of new publics, improvised citizens' movements and grassroots coalitions of often global reach, which frame political reality in new ways. The transformation of political order during crises encompasses not only the actions of political elites, organised civic society, citizens, but also the dialectic process within which these actions are presented, debated and evaluated. Thus, crisis governance is inextricably linked to public communication, not only in the narrow sense of crisis communication strategies implemented by the political elites but also in the wider sense of public exchange and debate between institutions and electorates. For political innovation to materialise, therefore, a crucial prerequisite is the sustained heightened visibility of alternative voices in the digital public sphere and the mainstreaming of these in established gatekeeping media. In this chapter, I test this potential by examining the plurality of voices in the digital sphere about the ongoing and well-publicised Euro/Greece crisis. 
In the first part of the chapter, I discuss the role of digital media in crisis communication and identify the conditions under which social media can spearhead a shift in public communication dynamics. In the second part of the chapter, I combine data from different sources to map how the process of crisis accountability has been unfolding in the case of the Eurocrisis. My empirical analysis subsequently takes a qualitative turn, as I profile the Euro/Greek crisis Twitter-sphere for the period of February-July 2015. The focus is particularly on the Twitter exchanges concerning the Greek referendum (Greferendum) that took place in July 2015. Which contributors have the highest visibility and what type of content do they produce? Which sources are favoured in retweets? On which aspects of the Eurocrisis/Greferendum did the Twitter-sphere focus? The findings are discussed in the third and final part of the article, where I revisit the concepts of influence, echoing and refraction in the social media sphere and consider their impact on the EU public sphere's capacity to nurture democratic crisis discourse.

\section{The role of social media in crisis communication}

Crises are disruptive: they interrupt the function of an organisation thus posing a threat to the achievement of commonly agreed goals and/or affecting the performance of collective problem-solving mechanisms - hence the need for rapid response. The increased levels of public communication due to the heightened media and public attention inevitably enhance the element of conflict in the public and political sphere. Perceptions are crucial, in that they affect the severity of the threat and subsequently the degree of consensus about the measures that need to be taken to address it (Coombs 2010; Liu et al. 2011). How public communication and contestation unfold during a crisis can be used as a central indicator for analysing type, dynamics and impact of that crisis on the transformation of political order and legitimacy (Seeger et al. 2003: 297). 
The basic expectation of any democratic leadership is that they will help safeguard society from the adverse consequences of crisis (Boin et al. 2005: 10). This is a complex process that rests on the capacity of organisations to observe and interpret signs of crisis, strategically respond, effectively communicate and have the ability to absorb lessons learned and implement them in order to avert future similar crises (Seeger et al. 2003; Allison and Zelikow 1999). The extent, quality, political approval and public legitimation of the introduced counter-crisis reforms are crucial factors that determine the success of a political leadership's attempts to terminate a crisis. The crisis accountability process is arguably the core phase of the crisis management process, as it is then that the outcomes of the previous steps are evaluated, setting the basis for institutional learning or undermining it altogether (Boin et al. 2005). Previous work on the link between crisis accountability in public discourse and the success of a crisis management strategy suggests that public reception is likely to be higher if the political actors involved in the design and implementation of counter-crisis measures a) enjoy elevated levels of public legitimacy; and/or b) follow a justification pattern that coincides with the dominant 'public sentiment', i.e. public actors justify counter-crisis measures in the same manner as the majority of the public/citizens (Brändström and Kuipers 2003).

In this effort, the media can be both allies and foes, but they can neither be sidestepped nor silenced, as this would go against the democratic principles of autonomy and accountability (Raboy and Dagenais 1992). The media provide the key communicative infrastructure not only for governing the crisis but also for the public legitimation of the crisis management measures (see the Introduction in this volume). Insofar as public opinion formation is concerned, the spectrum of opinions expressed and the justifications delivered in the media are the horizon for interpreting politics and thus become decisive for perceptions of political legitimacy (Schneider et al. 2007). 
Organisations, governments and political parties increasingly incorporate social media, in particular, in their crisis communication strategies (Wendling et al. 2013). Their aim is not only to reach out to the public/constituents but also to achieve better crisis mapping, as well as to improve internal team coordination and collaboration with external agencies, groups or actors (White 2012). Publics rely on social media, too, for information, official crisis services and informal, networked support, but also for voicing concerns and organising protests (Veil et al. 2011). As discussed in the Introduction of this volume, online media thus have the potential to 'reconfigure the dynamics of crisis communication'.

Indeed, research indicates that the medium used to convey a message during a crisis is as important as the message itself: Toni van der Meer and Piet Verhoeven (2013) emphasise the key role that social media (especially Twitter) play in the evolution and escalating character of crises. Friederike Schultz, Sonja Utz and Anja Göritz's (2011) experimental analysis on the effects of traditional and social-media strategies on the recipients' perceptions of reputation, as well as on the recipients' reactions and 'secondary' communications (such as the decision to comment on or share information), showed main effects of the medium. On the contrary, the message only appeared to affect recipients' secondary communications significantly. Crucially, Twitter was found - contrary to conventional wisdom - to lead to less negative crisis reactions than blogs and newspaper articles (Schultz et al. 2011: 25), while Twitter users were more likely to share the crisis communication message than blog users or newspaper readers. Sharing is especially likely to happen among Twitter users if the message was in the form of newspaper article since traditional media are perceived as more credible (Utz et al. 2013). Overall, and far from operating within echo chambers, Twitter users are found to be a key demographic in the success of a crisis communication strategy (Schultz et al. 2011: 25). 
Digital media and the Eurocrisis: an echo-chamber for blame-games or alternative public sphere?

As one of the latest in a string of critical situations in the European Union's history, the Eurocrisis - the economic, political and constitutional set of crises that have been testing the EU and its common currency construct since 2009 - is characterised by the same 'constraining dissensus' (Hooghe and Marks 2009; Statham and Trenz 2012) or 'differentiated politicisation' (de Wilde and Lord 2016) embodied by heightened public and media contestation that has accompanied every EU crisis since Maastricht. In this context, the Eurocrisis is constitutive of a particular kind of public discourse - polarised, emotionally charged, flaming but also frequently evoking democratic norms and European integration core values - that contests the legitimacy of governments, at national and European level (de Wilde et al. 2013; Michailidou et al. 2014; Cramme and Hobolt 2015). Misinformation; restriction of the diversity of political views; and manipulation of public opinion: all three have frequently been found to characterise the news coverage of Eurocrisis developments, particularly in regards to its toughest component, namely the case of Greece (Tracy 2012; Tzogopoulos 2013). Looking at some of the most sensationalist news coverage across EU countries, we could go as far as to say that the Euro/Greek crisis-fuelled politicisation is conducive to 'moral panic' public discourse (Cohen 1973; Thompson 2006). The public's wrath towards national and EU political leaders is evoked in the media on the basis, not solely of their decisions before or during the crisis, but of stereotypical views about their nationality being inherently evil or corrupt or lazy (Michailidou 2016; Wodak and Angouri 2014).

Nevertheless, a closer and more systematic look at the ways in which the Eurocrisis is reported in mainstream media (both offline and online) shows that journalistic bias is often in favour of EU and national political and technocratic elites, who dominate media coverage in professional news platforms (Michailidou et al. 2014). This combined with the seemingly 
'neutral' crisis framing that news reporters adopt - namely, most frequently only presenting the actions of various decision-makers as facts rather than provide commentary or analysis of those - leaves the technocratic hegemony discourse virtually unchallenged (D'Haenens et al. 2015, Mylonas 2014, Sousa and Santos 2014).

Empirical analysis of European online news spheres further shows that these are largely identical to the offline newspaper or television news environments, regarding news frames, newsworthiness criteria and reporting style of EU events (de Wilde et al. 2013; Michailidou et al. 2014). What sets online news platforms apart from their offline counterparts - both TV and newspapers - is the amount of information they offer on key EU events. Links to their democratising archived material or external sources make it possible for online news readers to either follow news stories back in time or to get several different perspectives on a story simultaneously. Apart from these information 'plus points', the community of news readers is still gathered around the same topics of relevance and exposed to a form of public opinion and will formation that feeds democracy in a national context. In this respect, the online EU sphere mirrors the Europeanisation of offline news spheres (Wessler et al. 2008; Koopmans and Statham 2010; Liebert and Trenz 2009): nationally 'confined' news reporting survives online too. Not surprisingly then, politicians from the national political arenas are also the most visible actors in online news-making.

There is, however, already some evidence that social media could offer an alternative line of discourse vis a vis the Euro/Greek crisis (e.g. Touri and Kostarella 2016), but this is primarily drawn from the Greek digital sphere - thus lacking a comparative dimension - or it tends to be limited in terms of its data scope. The analysis presented in this chapter expands the pool of data to the wider Twitter-sphere, thus capturing the dynamics of Eurocrisis discourse beyond the linguistic and geographical spheres of particular countries. The quantitative part of the analysis further draws on a large-N sample of tweets, which allows for 
a closer-to-reality reconstruction of the Eurocrisis Twitter-sphere. What remain relatively unchanged, compared to previous research, are the core questions this empirical study addresses: Does the social media public sphere offer an outlet for alternative Eurocrisis discourses? Does it amplify the spectre of voices publicly raised about the issue? Moreover, if it does, is there any indication that this extended pluralism could find its way into mainstream news media flows? Ultimately, these are questions as much about inclusiveness as they are about engagement. In order to address these issues, two concepts are deployed, namely echo and refraction. Their definition and operationalization in the case of the Eurocrisis Twittersphere are discussed in detail in the following part.

\section{Conceptualising public engagement: echo and refraction on social media}

Research on the democratising potential of digital communication has consistently focused on the plurality, inclusiveness and empowerment of 'ordinary voices' afforded by the digital public spheres. Scholars have long been divided in their assessment of these affordances, with the most critical ones pointing to the fragmenting effects of digital and social media on the political sphere (McNair 2009; see also the Introduction and the chapter by Bossetta et al. in this volume). Much of the fragmentation of the online public sphere approach is captured in and inspired by Cass Sunstein's influential conceptualisation of the internet as mostly a sphere for social networking and individual profiling (Sunstein 2007), which creates biased echo chambers of like-minded individuals instead of focal points for political news. From this perspective, digital communication thus promotes the isolation of users, who are less prepared to engage in community interactions 'off line', ultimately accelerating the shift towards postdemocracy, whereby fragmented and politically disempowered audiences are deprived of their possibilities of representation and collective will formation (Crouch 2004). 
Nevertheless, more recent empirical attempts to capture the nature of online political communication repeatedly dispute the echo-chamber approach, pointing instead to a more mixed picture of echoes, refractions and even innovation in the digital public sphere. Crucially, scholars investigating the empowering or restraining effect of social media debating helpfully remind us of external factors that can predict individuals' online behaviour and likelihood to engage with 'the Other' in social media, such as ideological orientation (for example, liberals or democrats are more likely to engage in cross-ideological dissemination; Colleoni et al. 2014). When Pablo Barberá, John Jost, Jonathan Nagler, Joshua Tucker and Richard Bonneau (2015) estimated the ideological preferences of 3.8 million Twitter users using a data set of nearly 150 million tweets concerning 12 political and non-political issues, they found that although the echo-chamber effect is prevalent in conversations regarding political issues, it is not so in the case of other current events, including terrorist attacks and sports events. Consequently, the authors concluded that previous research on the echochamber effect of social media 'may have overestimated the degree of ideological segregation' that the digital public sphere facilitates (Barberá et al. 2015: 1531). Their findings are matched by the work of Hywel Williams, James McMurray, Tim Kurz and Hugo Lambert (2015). Their network analysis of social media discussions of climate change confirmed the presence not only of echo chambers of like-minded individuals but also of mixed-attitude communities in which sceptics and activists frequently interacted and which were conducive to less polarisation and more debate.

Bernhard Rieder (2012) captures this diversity of the online public sphere with the term 'refraction chamber': Even when tweets concerning an event are repeated (retweeted) thousands of times, they will not always be the same. By proposing that messages on Twitter are treated as refracted, rather than just diffused, Rieder allows for the meaning, rhetoric and ideology of both the message and the manner it is dispersed to be taken into account in the 
analysis of social media communication. Rieder's (2012) empirical research on the French Twitter-sphere has further found that often the most popular tweets are those that 'add a "twist" to the topic and "spin" it in a certain way, i.e., that "refract" it'. Although the Twitter-sphere concerning a given topic is usually limited regarding the diversity of reference points, for Rieder this 'commonality is the result of labour [of Twitter users] on different levels and a product rather than an effet pervers, an unintended consequence' of Twitter communication (Rieder 2012).

For the analysis of the Eurocrisis Twittersphere, echo and refraction are used as definers of different degrees of inclusiveness ('space' allowed for multiple opinions and voices) and of user engagement, whereby the message is reproduced as a result of unquestioned dominant influencers or as a result of the Twitter user's conscious decision to adopt and adapt the message (Table $\mathrm{X}$ below). As explained in the following section, the operationalization of the echo/refraction concept required a combination of quantitative and qualitative processing of the Eurocrisis Twittersphere.

Table X.1: The echo-refraction matrix for capturing inclusiveness and engagement in the Eurocrisis Twittersphere; Source: the author drawing on Rieder 2012.

\begin{tabular}{lll}
\hline & Inclusiveness & User engagement \\
\hline Echo & Like-minded individuals; no & Minimal; users reproduce (retweet) \\
chamber & alternative voices or views & dominant view with no changes or \\
& & added comments \\
Refraction & Non-homogenous sphere; & Notable; users reproduce (retweet) \\
chamber & more than one dominant view & dominant view with their perspective \\
& present & added \\
&
\end{tabular}




\section{Method}

Taking cue from Elizabeth Dubois and Devin Gaffney's (2014) work on the identification of influencers on Twitter, which shows that different operationalisations of influence reveal different types of influencers within a Twitter network, the collected Eurocrisis tweets were processed both quantitatively and qualitatively. More specifically, tweets' metadata were quantitatively processed to determine the quantity of connections of each user (which are more likely to identify such political elites as news media and politicians as influencers; Dubois and Gaffney 2014) and the amount of retweets they received. Moreover, the extent of message duplication within the Eurocrisis Twittersphere was calculated in order to determine: a) the type of communication (echo or refraction signified by the degree of 'twists and spins' introduced to an original/seed tweet), and b) the extent of inclusiveness of voice (calculating number of duplicate 'seed' messages and profiling their creators).

Semi-automated coding was additionally used to capture the degree of homogeneity/divergence of the Eurocrisis Twittersphere. For this purpose, sentiment analysis was deployed as a proxy indicator for the presence of one or more dominant views. Previous research has shown that positive sentiment is typically linked to exchanges between likeminded individuals (Hywel et al. 2015). Users in mixed-attitude communities, where we are more likely to observe refraction rather than echo, are less significant to hold sharply polarised views, but more liable to express negative sentiment towards other users with differing views (Hywel et al. 2015). For the sentiment coding of the Euro/Greece crisis dataset, we used DiscoverText's (Texifter 2016) universal sentiment code set (positive/negative sentiment), which is based on a vocabulary of positive and negative words in several languages.

The content of the most popular tweets within specific threads (\#Greferendum and \#Grexit) was further coded to capture the quality of messages. Each tweet was classified 
according to whether it was purely informational or contained emotions and/or opinion; the latter being traits that are more likely to identify political commentators and bloggers as per Dubois and Gaffney 2014. In addition to DiscoverText, we also used hashtagify.me (Cybranding 2016) for the collection and processing/coding of the data.

\section{Sampling}

The empirical component discussed in this chapter draws on Twitter data collected in the period March-July 2015, using DiscoverText (Texifter 2016) to import directly 'live' Eurocrisis tweets through Twitter's public API. In total, 4,8 million Tweets were collected, using several keywords to define the search (among which: 'Eurocrisis', 'EU', 'Greece', 'Germany', 'Eurogroup', 'Tsipras', 'Merkel', 'SYRIZA', 'Grexit', 'Greferendum', 'Brussels', 'Juncker', 'Troika'). The keywords were derived from a preliminary analysis with hashtagify.me of dominant hashtags used about the Eurocrisis.

The subsequent sampling of this 'mega' archive unfolded in several steps using DiscoverText's tools for automated random sampling and refining of archives. We first scanned for peaks in the number of tweets produced, and the three days with the highest number of tweets (19 March, 22 May and 1 July 2015) were selected as the Twitter material from which a random sample was extracted for coding. In total 4695 tweets were quantitatively coded out of a total of 319776 produced during these three days (99 percent confidence level; 2 percent confidence interval). After identifying the main hashtags and topics contained in this sample, we returned to the master archive to pull out further items concerning these top hashtags/topics.

The findings presented in this chapter are based on the dataset 'Greferendum'. This includes all the tweets in the original archive referring to the referendum that took place in Greece for the citizens to decide whether the country should accept the bailout conditions 
proposed by the European Commission, the International Monetary Fund and the European Central Bank to the Eurogroup of 25 June 2015. The referendum was declared by the Greek government on 27 June 2015 after weeks of failed attempts to come to an agreement with the Eurozone partners, the IMF and the European Commission and intense public rhetoric regarding Greece's potential exit from the single currency (Papadimas and Kirschbaum 2015). After a very brief campaigning period, the referendum took place on 5 July 2015. Over six million Greek voters turned out at the polls (62.5 percent of registered voters) and rejected the bailout proposal by 61.31 percent, against 39 percent who voted in favour. The 'Greferendum', as it became more commonly known through a popular media meme, was the first referendum to be held in Greece since the restoration of democracy in 1974 and the only one in the country's modern history not to concern the form of government.

This particular Eurocrisis event, and more specifically the brief campaign period that led up to the referendum, was selected for further study, as the controversy that surrounded it resulted in social media 'storm', thus providing an ideal opportunity to observe polarisation, sentiment and participation on Twitter. From the moment it was announced, the Greferendum caused great polarisation in Greece, global media interest and intense clashes among national political elites both in Greece and across the EU (Walter et al. 2016). During the short campaign period, the Greek government defended its decision to allow the Greek citizens to have a say on the terms and conditions proposed in what subsequently became known as the 'Third Memorandum'. On the contrary, Greek opposition parties and politicians in power in other EU member states declared in all tones that a negative vote on the draft proposal would equal a vote to leave the Eurozone, and potentially also the EU (Morris 2015). EU senior officials were also none too pleased about the decision of the government to put the bailout terms to popular vote and made their displeasure known, some less subtly than others (Elliott et al. 2015). Fringe extreme right-wing and Eurosceptic parties across the union rejoiced at 
what they saw as potentially the starting point for the unravelling of the EU (Clavel 2015). At the same time, several EU member state opposition parties, mostly on the left, as well as a host of national and international intellectuals and economics experts weighed in the public debate expressing their support towards the Greek government's decision. They also expressed their support for a 'No' vote that could potentially lead to a 'Grexit' from the Eurozone and/or their solidarity towards the Greek people, who were seen as being cornered by both their national political establishment and their EU partners (Krugman 2015; Stiglitz 2015).

Selecting all tweets relevant to the Greferendum campaign (27 June - 4 July 2015) from our master Eurocrisis archive returned 6,923 tweets. To put this in context, we analysed approximately one in every 53 tweets created about this event during the campaign period; this calculation is based on the entire universe of tweets created about this event at the time. Approximately 365,000 relevant tweets were found in the historical public Twitter archive, using DiscoverText's Sifter tool to access Twitter's historical archive (powered by Twitter's enterprise API platform 'Gnip'). In a first step, we used DiscoverText to process this subarchive's metadata, such as the number of followers per user, geolocation, the number of retweets per item included in the archive, as well as hashtag and word clouds. In a second step, we used DiscoverText to process the archives for duplicates. Items are considered to be duplicates if their text content, excluding whitespace, is the same but with different metadata, i.e. each of the near-duplicate retweets has the meta-signature of a unique user. This processing enabled us to understand the nature of the engagement with the topic and hashtag Greferendum better. Subsequently, the authors of the most popular seed tweets, as well as the authors of high number of re-tweets within the sub-archive (items with more than 100 retweets), were classified according to the following categories: Citizen; Twitterpreneur; News source; Expert; National Politician; EU politician/official; NGO/activist 
organisation/representative; and Entertainer/Celebrity. The profiles of the ten most popular authors within the Greferendum-tweet archive were then analysed in detail, to unpack the above author categories further.

\section{Findings}

\section{Archive profile}

The Greferendum archive showed that this particular Eurocrisis topic brought together a potential network of over 43 million Twitter users (unique users within the archive, plus their followers). With its epicentre predictably in Greece and most of its members located in Europe, the Greferendum Twittersphere had a global reach, from the Americas and Australia to Russia, Dubai, Nigeria, Kenya, China, Thailand and Japan. This indicates substantial inclusiveness regarding geographic proximity to the topic/event. Regarding content, however, analysis of the hashtags used in this Twittersphere shows little variety - as regards 'owning' the content that they reproduce or introducing a new angle - in the ways that Twitter users frame the topic. 


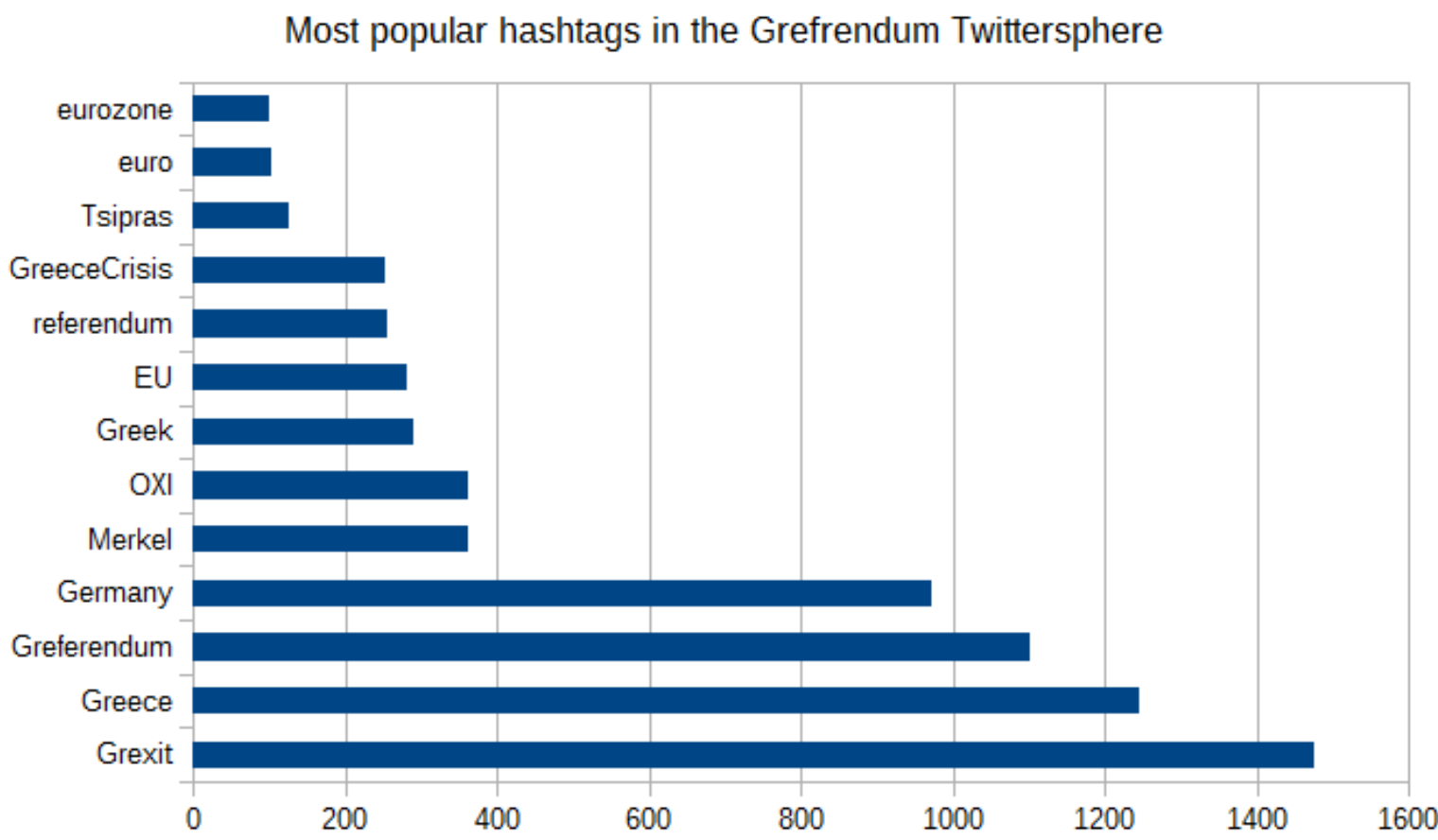

Similarly, when it comes to Twitter users with the highest number of mentions $(>80$ mentions), the list is dominated by news media organisations (Reuters, dpa International, the Telegraph), individual journalists and just one prominent politician, former Greek Finance Minister Yanis Varoufakis. Two citizen-users who feature on the top most mentioned are there not because of their popularity but because a more prominent Twitter user mentioned them in their original message, which was then duplicated (replicated verbatim) by several other users.

\section{Duplication and sentiment}

The semi-automated classification process showed both high numbers of duplication and negative feelings. In particular, nearly half of the Greferendum dataset (3368 items) comprised of duplicates, classified in a total of 308 groups. Each group includes the seed tweet plus all its exact duplicates. The top ten groups regarding numbers of duplicates made up for 17 percent of the entire Greferendum archive (10 seed tweets; 1197 items in total). 
In terms of sentiment, again two-thirds of all Greferendum tweets (61 percent) were classified as 'negative'. This means that they expressed among other things scepticism; rejection; fear; unwillingness or inability to act; disappointment; anger; sarcasm/ridicule or hostility towards particular actors or possible referendum outcomes, as the following tweet excerpts illustrate.

Tweet A: 'Grexit would be catastrophic: German foreign minister'

Tweet B: 'Elegant skewering of "intellectual exhaustion" in the Eurozone'

Tweet C: "Juncker proposal "unwelcome surprise" says Tsipras - Greek wants debt sustainability, no Grexit [sic]'

Tweet D: 'KICK GREECE OUT \#auspol \#Grexit'

Tweet E: 'Poor Schauble [sic] must be driving to nearest pharmacy right now to buy himself some Alka-Seltzer after those last Tsipras' comments'

At first glance, this first general classification of sentiment, which indicates a heterogeneous Twitter-sphere where diverse voices are allowed to be heard, appears to be in contrast with the high level of duplication and clustering (verbatim or slightly altered seed tweets circulated in great numbers) also found in the dataset. Nevertheless, when further classifying negative and positive tweets, according to the actor(s) and dimensions of the Eurocrisis or Greferendum they addressed, we found that tweets belonged to four general categories: Greferendum/Greece negative, Greferendum/Greece positive, EU/Germany negative, EU/Germany positive. This finding, in combination with the high volume of duplicated tweets, suggests that the Greferendum micro Twitter-sphere, in particular, was highly polarised, rather than plural. To be more precise, while this was certainly not a sphere of likeminded individuals only, the nature of the topic (a Yes/No polarising plebiscite and the 
already highly polarising Eurocrisis itself) evidently also limited the range of views and influential voices present in the Twitter-sphere.

\section{Profiling of top influencers}

Of the top ten seed tweets, the one with the highest number of exact duplicates was one by Greek politician and media's favourite Yanis Varoufakis (@yanisvaroufakis, 779000 followers). The tweet was a response to a German citizen Twitter user (i.e. a Twitter user with less than 1000 followers and no particular expertise listed on their profile) regarding the role of France in Greece's negotiations with its creditors.

Yanis Varoufakis (@yanisvaroufakis,6:45 PM, 9 June 2015): ‘@[...] Quite. France is key. Grexit $=$ Por-xit $=$ Spa-xit $=$ Ita-xit, which would then lead Germany to cut France off. Make no mistake'.

This tweet was part of a lengthy exchange mostly between these two, but several other Twitter users had also contributed. What is interesting about this item is that it was created before the Greferendum had even been announced, at the height of public debates and speculation regarding Greece's possible exit from the Eurozone. Nevertheless, the tweet remained popular for an extended period and was quickly linked by Twitter users to the Greerendum debate. The seed tweet was originally directly tweeted from @ yanisvaroufakis profile 332 times (second-most retweeted item in that particular thread). However, in our data archive alone, its 335 duplicate tweets were further shared (retweeted) a total of 100,217 times, making this tweet the most successful regarding visibility in our archive. Yanis Varoufakis is also the most frequently mentioned and most 'replied to' Twitter user in our dataset even though his profile is not among the most followed (with millions of followers, 
Reuters, the BBC, RT and other international news media platforms far surpass Varoufakis's following). One of the key reasons behind this particular politician's favourable influence of the social media and broader public sphere is his ability to 'refract'. Varoufakis takes a topic (in the tweet examined here, Grexit) and 'puts his personal stamp on it' (Rieder 2012), by presenting it in a slightly different manner. He links Grexit to the exit of several other countries from the Eurozone and uses 'catchy' language that lends itself to becoming a slogan.

A closer look at the rest of the Top-10 seed tweets revealed the presence of one economist (Bloomberg Euro-area economist Maxime Sbaihi, @ McSba, with 5,546 followers) and three news platforms with international reach, namely: Reuters (@Reuters); the Telegraph (@Telegraph); and dpa-International, the international newswire of the German Press Agency (@dpa_intl). All seed tweets from these sources have a mostly negative sentiment, all present the official positions and reactions of political actors/governments towards the Greek referendum without comment, and nearly all mention Grexit in text or as a hashtag.

Second-most duplicated source in our archive, Reuters, with 14.3 million followers of its Twitter profile, had a tweet in the top-seeds list from its Breaking News stream, concerning a statement by German Chancellor Angela Merkel regarding Germany's position on a new memorandum proposal before the Greek referendum.

Reuters Top News (@Reuters, 35:54 PM, 30 June 2015): 'BREAKING: Merkel told lawmakers Germany cannot consult on a new proposal before Greek referendum'.

The breaking-news worthiness of this piece of information can only be appreciated when read in the political context of the time. The Greek government was hoping to convince its EU partners and lenders to consider its counter-proposal to the so-called Juncker draft 
memorandum that was being put up for the public vote, before said referendum were to take place. The aim was two-fold: on the one hand, the Greek government wanted to show that it did have a counter-plan and was not only stalling for time. On the other hand, the Government was aiming to quell the accusations both in Greece and abroad that it had called the referendum because its ultimate goal was a Greek exit from the Eurozone. Angela Merkel's refusal to consider any proposals before the referendum would instead maintain the debate around the possibility of a Grexit. The Reuters tweet was directly retweeted from @ Reuters profile 185 times and had 170 exact and 113 near-duplicates in our Greferendum archive, while these duplicates went on to be retweeted a total of 32,461 times.

In addition to established news media platforms, the Top-Ten list of most copied Greferendum tweets also includes a Greek journalist, Eleni Varvitsiotis (@Elbarbie, 23,000 followers), who is EU correspondent for the right-wing broadsheet newspaper Kathimerini and the television channel SKAI TV. Her tweet summarising the reaction of EU heads of state to the Greek government's decision to hold a referendum had 135 exact duplicates in our archive, which were further retweeted 18,801 times within a potential network of at least 154,865 Twitter users (the users who originally reproduced Eleni Varvitsiotis' tweet, plus their followers). Varvitsiotis is one of several Greek journalists, analysts and Twitterpreneurs who played a key role in the reporting of the Greek crisis in 2015 and who, despite their relatively modest following, can be considered as political influencers in the Greek case as their tweets are monitored by prominent EU/Eurocrisis Twitter actors in other countries and at EU level. For example, Varvitsiotis' seed tweet was reproduced, among others, by Paavo Teittinen, a journalist for the Finnish Helsingin Sanomat, and Hugo Dixon (@Hugodixon, 35,000 followers), British author and Reuters columnist (previously at the Financial Times).

Breaking with the trend of journalists and news media organisations to report on the Greferendum from a seemingly neutral, yet definitively negative in sentiment, perspective, is 
the British journalist Shehab Khan (@ShehabKhan, 21,100 followers), whose tweet also features in the Top-Ten list of most replicated items:

Shehab Khan (@ShehabKhan, 9:03 PM: 3 July 2015): ‘1953 - Greece’s finance minister signs a treaty to cancel $50 \%$ of Germany's debt \#Grexit'.

The tweet is accompanied by a photo of then Greek Finance Minister Konstantinos Karamanlis signing the accord. With 81 direct retweets from his profile and 61 exact duplicates in our archive, which were further retweeted 3,953 times in a potential network of at least 49,269 Twitter users, Khan's tweet does not quite match the visibility of Greferendum influencers such as Yanis Varoufakis or Reuters. Nevertheless, his tweet is part of an influential cluster (near-duplicate tweets) that comprises 468 tweets in our archive, including two more seed tweets from the Top-Ten list. All these tweets (repeated another 35,414 times within the archive users' immediate networks) concern the 1953 London Debt Accords when European and world leaders - among them the Greeks - cancelled West Germany's debt. Some tweets within this cluster make specific mention of how Greece agreed to write off Germany's debt in 1953, while others refer to the debt write-off as a general reminder to Germany of its obligations towards the rest of Europe and/or the world. Nearly all tweets contain a photograph, either of the Greek Finance Minister or other European leaders signing the 1953 London Debt Accords.

What makes this cluster particularly interesting is that it is one of the few instances certainly the most popular such in our archive - when we see evidence of user intervention, albeit minimal, in the original tweet's text. These traces of content refraction become even more encouraging when we look at the profile of the tweets' source. Rather uncommonly for the Greferendum thread, this is an online article written by the Jubilee Debt Campaign (2015), 
a UK-registered charity organisation that brings together national and local/regional organisations and groups mostly in the UK. The Jubilee Debt Campaign defines itself on its website as 'a global movement' whose aim is to demand 'freedom from the slavery of unjust debts and a new financial system that puts people first'.

\section{Discussion}

The monitoring and analysis of the Eurocrisis Twittersphere in 2015 show that although Twitter is inclusive in its potential, in practice, the voices that tend to have the most clout in times of crisis are those of established public actors (journalists or news media sources, celebrity politicians, experts and less so Twitterpreneurs). Occasionally, individuals from the general public do get their Twitter name established strongly enough to enter the list of top political influencers, but this is not necessarily because of their views. Instead, they tend to have a strong following on Twitter which replicates (retweets) any link they reproduce, but the opinions contained in the original message are those of others, not their own. It is difficult, therefore, to talk of refraction in the case of the Eurocrisis Twittersphere: all the evidence points initially to echo chambers, replicating the messages of a handful of Twitter users.

The fact that most of these 'super-users' were found to be influential public sphere actors is in line with previous research regarding patterns of social media users' behaviour in times of crisis (Schultz et al. 2011), whereby crisis news provided by established news media tend to get shared more by Twitter users, as they may be considered more trustworthy sources of information. The Eurocrisis/Greferendum Twitter-sphere crowd mostly opted for sharing tweets from sources that are perceived as reliable, with globally-established mainstream news media being the main favourite. Because of the prominence of influential public actors in the analysed public sphere, and more importantly, because the majority of repeated tweets comes from the very particular prominent public agent that are the news media, it would be rather 
inaccurate to describe the Greferendum Twittersphere as merely a set of echo chambers. Instead, what the findings show is that traditional news media are firmly holding on to their position as key mediators and gatekeepers of the political public sphere against all expectations to the contrary. More specifically to the case of the Euro/Greek crisis, however, the finding of a primarily news media-driven message flow suggests that the systematic biases found in the reporting of offline news media organisations, as discussed earlier in this chapter, have also permeated the sphere of social media, limiting its potential to foster alternative debates.

At the same time, the main encouraging point that emerges from the analysis presented here is that Twitter offers the possibility to ordinary citizens to become influential public sphere actors themselves (Twitterpreneurs), albeit to a limited extent so far. Even though we cannot speak of inclusiveness of views in the case of the Greferendum Twittersphere, we do find some evidence of inclusiveness of voice. This inclusiveness is not so much in the form of 'ordinary' citizens-users, but of regional/national actors, such as national correspondents or financial experts, whose presence does not necessarily have a global bearing or immediately recognisable international influence; but who are important in the streaming and framing of views within this particular Twittersphere. Such actors could fit under Marwick and boyd's (2011) concept of 'micro-celebrity' Twitter users, in that their interactions with their 'network audience' can elevate their views to mainstream level, potentially broadening the variety of opinions represented in the social media sphere.

Two caveats are necessary to note here in so far as the conclusions drawn from this research are concerned. Firstly, the analysis presented in this chapter concerns a very particular type of public discourse: not only does the examined Twitter-sphere constitute part of crisis communication, but it is also a mostly elite-driven, top-down public sphere, very much reliant on inputs by institutional actors. Therefore, it is possible that the role of Twitter 
as a medium that enhances participation, engagement and pluralism in the public sphere is different if one examines various types of event spheres or social media threads. Secondly, the findings discussed here are medium-specific: Twitter's apparent close link, if not dependency, on news media, may well not be confirmed for other social media, such as the more community-enhancing Facebook or image-driven Instagram.

Overall, however, the findings allow for bittersweet optimism as regards the idea of 'loose public Europeanism' put forward in the Introduction chapter of this volume. Indeed, we can glimpse a sense of Europeanness that does not presuppose a shared understanding of what it means to be European in the ways that the Greferendum event was framed. Rather neatly divided into two main camps, Twitter users either reproduced the mainstream discourse of EU responsible leaders issuing warnings in all tones that the referendum was an irresponsible and incomprehensible act to declare, bringing Greece a step closer to being ejected from the Eurozone and possible the EU family altogether. Alternatively, they sided in solidarity with the Greek government, reproducing critiques against austerity measures and reminding the rest of Europe how past debt 'trespasses' were forgiven by those whom today stand accused of fiscal profligacy. This loose European demos debating the Euro/Greek crisis is not so much an active contributor to shaping the collective voice of citizens, as it is an echo chamber in which established public sphere gatekeepers continue to determine the discourse on the future of Europe.

\section{Acknowledgements}

The research presented in this chapter is part of the EURODIV research project, carried out at the ARENA Centre for European Studies under the project leadership of Professor Erik Oddvar Eriksen. The funding of the project by the Research Council of Norway is gratefully acknowledged. Many thanks go to Tor Kristian Haldorsen, research assistant at ARENA, who 
very efficiently tested the coding schedules and subsequently processed large parts of the Eurocrisis Twittersphere data. 


\section{References}

Allison, G. T. and Zelikow, P. (1999). Essence of Decision. 2nd edition, New York/Harlow: Longman.

Barberá, P., Jost, J. T., Nagler, J., Tucker, J. A. and Bonneau R. (2015). Tweeting From Left to Right: Is Online Political Communication More Than an Echo Chamber? Psychological Science, 26(10), pp. 1531-1542.

Boin, A., Hart, P., Stern, E. and Sundelius, B. (2005). The Politics of Crisis Mangagement: Public Leadership Under Pressure. Cambridge: Cambridge University Press.

Brändström, A. and Kuipers, S. (2003). From 'Normal Incidents' to Political Crises: Understanding the Selective Politicization of Policy Failures. Government and Opposition, 38(3), pp. 279-305.

Clavel, G. (2015). How France's National Front looks to capitalize on the Greferendum. Huffington Post [online], 29 June 2015. Available at: http://www.huffingtonpost.com/2015/06/29/greece-referendum-national-front_n_7691166.html [Accessed 10 August 2016].

Cohen, S. (1973). Folk Devils and Moral Panics. St. Albans: Paladin.

Colleoni, E., Rozza, A. and Arvidsson, A. (2014). Echo Chamber or Public Sphere? Predicting Political Orientation and Measuring Political Homophily in Twitter Using Big Data. Journal of Communication, 64(2), pp. 317-332. DOI: 10.1111/jcom.12084.

Coombs, W. T. (2010) Parameters for crisis communication. In: W. T. Coombs and S. J. Holladay, eds, The Handbook of crisis communication. Oxford: Wiley-Blackwell, pp. 1753.

Cramme, O. and Hobolt, S.B. (eds) (2015). Democratic politics in a European Union under Stress. Oxford University Press: Oxford.

Crouch, C. (2004). Post-Democracy. Cambridge: Polity Press. 
Cybranding (2016). hashtagify.me Twitter Hashtags search engine: http://hashtagify.me [Accessed 10 August 2016], London: CyBranding Ltd.

de Wilde, P. and Lord, C. (2016). Assessing actually existing trajectories of EU politicisation. West European Politics, 39(1), pp. 145-163.

de Wilde, P., Michailidou, A. and Trenz, H. J. (2013). Contesting Europe. Essex: ECPR Press.

D'Haenens, L., Joris, W. and Papathanassopoulos, S. (2015). Crisis of the news: The framing of the Euro crisis and the 'Greek problem'. In: J. Trappel, J. Steemers and B. Thomass, eds, European media in crisis: values, risks and policies. New York, Oxon: Routledge Taylor and Francis Group, pp. 118-132.

Dubois, E. and Gaffney, D. (2014). The Multiple Facets of Influence: Identifying Political Influentials and Opinion Leaders on Twitter. American Behavioural Scientist, 58(10), pp. $1260-1277$.

Elliott, L., Wearden, G., Watrt, N. and Smith, H. (2015). Europe's big guns warn Greece voters that a no vote means euro exit. The Guardian [online], 30 June 2015. Available at: https://www.theguardian.com/business/2015/jun/29/greek-crisis-referendum-eurozonevote-germany-france-italy [Accessed 10 August 2016].

Hooghe, L. and Marks, G. (2009). A Postfunctionalist Theory of European Integration: From Permissive Consensus to Constraining Dissensus, British Journal of Political Science, 39(1), pp. 1-23.

Hywel, W. T.P., McMurray, J. R., Kurz, T., Lambert, F. H. (2015). Network analysis reveals open forums and echo chambers in social media discussions of climate change. Global Environmental Change, 32, pp. 126-138. Available at: http://www.sciencedirect.com/science/article/pii/S0959378015000369 [Accessed 23 August 2016]. 
Jubilee Debt Campaign (2015). How Europe cancelled Germany’s debt in 1953.

jubileedebt.org.uk, 26 February 2015. Available at: http://jubileedebt.org.uk/reportsbriefings/briefing/europe-cancelled-germanys-debt-1953 [Accessed 10 August 2016].

Koopmans, R. and Statham, P. (eds) (2010). The Making of a European Public Sphere: The Europeanisation of Media Discourse and Political Contention. Cambridge: Cambridge University Press.

Krugman, P. (2015). Greece over the brink. nytimes.com [online], 29 June 2015. Available at: http://www.nytimes.com/2015/06/29/opinion/paul-krugman-greece-over-thebrink.html?_r=2 [last accessed: 10 August 2016].

Liebert, U. and Trenz, H. (2009). Civil society and the reconstitution of democracy in Europe: Introducing a new research field. Policy and Society, 28(1), pp. 1-9.

Liu, B.F., Austin, L. and Jin, Y. (2011). How publics respond to crisis communication strategies: The interplay of information form and source. Public Relations Review, 37(4), pp. 345-353.

Marwick, A.E. and boyd, d. (2011). To see and be seen: celebrity practice on Twitter, Convergence 17 (2): 139-157, doi: 10.1177/1354856510394539.

McNair, B. (2009). The internet and the changing global media environment. In: A. Chadwick and P.N. Howard, eds, Handbook of Internet politics. London: Routledge, pp. 217-229.

Michailidou, A. (2016). The Germans are back: Identity, stereotypes and Euroscepticism in crisis-stricken Greece. National Identities, $18, \quad$ pp. 1-19. DOI:10.1080/14608944.2015.1113242.

Michailidou, A., Trenz, H. J. and de Wilde, P. (2014). The Internet and European Integration. Berlin: Barbara Budrich.

Morris, C. (2015). Analysis-Greece debt crisis: Tsipras announces bailout referendum. 
BBC [online], 27 June 2015. Available at: http://www.bbc.com/news/world-europe$\underline{33296839}$ [last accessed 10 August 2016].

Mylonas, Y. (2014). Crisis, austerity and opposition in mainstream media discourses of Greece. Critical Discourse Studies, 11(3), pp. 305-321.

Papadimas, L. and Kirschbaum, E. (2015). Greek PM tears into lenders as euro zone prepares 'Grexit'. Reuters [online], 16 June 2015. Available at: http://www.reuters.com/article/useurozone-greece-idUSKBN0OW16320150616?utm_source=twitter [Accessed 10 August 2016].

Raboy, M. and Dagenais, B. (eds) (1992). Media, Crisis and Democracy: Mass Communication and the Disruption of Social Order. London: Sage.

Rieder, B. (2012). The refraction chamber: Twitter as sphere and network. First Monday, 17(11), pp. 1-16. DOI: http://dx.doi.org/10.5210/fm.v17i11.4199.

Schneider, S., Nullmeier, F. and Hurrelmann, A. (2007). Exploring the communicative dimension of legitimacy: Text analytical approaches. In: A. Hurrelmann, S. Schneider and J. Steffek (eds) Legitimacy in an Age of Global Politics. London: Palgrave MacMillan, pp. $126-55$.

Schultz, F., Utz, S. and Göritz, A. (2011). Is the medium the message? Perceptions of and reactions to crisis communication via Twitter, blogs and traditional media. Public Relations Review, 37(1), pp. 20-27.

Seeger, M. W., Sellnow, T. L. and Ulmer, R. R. (2003). Communication and organizational Crisis. Westport/London: Praeger.

Sousa, H. and Santos, L. A. (2014). Portugal at the Eye of the Storm: Crisis, Austerity and the Media. Javnost - The Public, 21(4), pp. 47-61.

Statham, S. and Trenz, H. J. (2012). The politicization of Europe: contesting the constitution in the mass media. London: Routledge. 
Stiglitz, J. (2015). How I would vote in the Greek referendum. The Guardian [online], 29 June 2015. Available at: https://www.theguardian.com/business/2015/jun/29/josephstiglitz-how-i-would-vote-in-the-greek-referendum [last accessed: 10 August 2016].

Sunstein, C.R. (2007). Republic.com 2.0. Princeton, NJ: Princeton University Press.

Texifter (2016). DiscoverText text analytics. Massachusetts: Texifter LCC. Available at: http://discovertext.com [last accessed 10 August 2016].

Thompson, K. (2006). The history and meaning of the concept. In: C. Critcher (ed.) Critical Readings: Moral Panics and the Media. Berkshire/New York: Open University Press, pp. 60-66.

Touri, M. and Kostarella, I. (2016). News blogs vs mainstream media: measuring the gap through a frame analysis of Greek blogs. Journalism, published online before print May 16, 2016, pp. 1-19. DOI: 10.1177/1464884916648097.

Tracy, J. F. (2012) Covering 'Financial Terrorism'. Journalism Practice, 6(4), pp. 513-529.

Tzogopoulos, G. (2013). The Greek crisis in the media: stereotyping in the international press. Farnham: Ashgate.

Utz, S., Schultz, F. and Glocka, S. (2013). Crisis communication online: How medium, crisis type and emotions affected public reactions in the Fukushima Daiichi nuclear disaster. Public Relations Review, 39(1), pp. 40-46.

van der Meer, T.G.L.A. and Verhoeven, P. (2013). Public framing organisational crisis situations: Social media versus news media. Public Relations Review, 39(3), pp. 229-231.

Veil, S. R., Buenhner, T., and Palenchar, M. J. (2011). A work-in-process literature review: Incorporating social media in risk and crisis communication. Journal of Contingencies and Crisis Management, 19(2), pp. 110-122. DOI: 10.1111/j.1468-5973.2011.00639.x.

Walter, S., Dinas, E., Jurado, I. and Konstantinidis, N. (2016). Disintegration by popular 
vote: Expectations, foreign intervention and the vote in the 2015 Greek bailout referendum, paper prepared for the EPSA meeting 2016, Brussels, 23-25 June 2016.

Wendling, C., Radisch, J. and Jacobzone, S. (2013) 'The use of social media in risk and crisis communication', OECD Working Papers on Public Governance No. 24. DOI: 10.1787/5k3v01fskp9s-en [last accessed 2 February 2016].

Wessler, H., Peters, B., Brüggemann, M., Kleinen-von Köningslöw, K. and Sifft, S. (eds) (2008). Transnationalization of public spheres. Basingstoke: Palgrave MacMillan.

White, C.M. (2012). Social media, crisis communication, and emergency management. Boca Raton/London/New York: CRC Press, Taylor \& Francis Group.

Williams, H. T.P., McMurray, J. R., Kurz, T. and Lambert, F. H. (2015). Network analysis reveals open forums and echo chambers in social media discussions of climate change. Global Environmental Change, 32, pp. 126-138. Available at: http://www.sciencedirect.com/science/article/pii/S0959378015000369 [Accessed 23 August 2016].

Wodak, R. and Angouri, J. (2014). From Grexit to Grecovery: Euro/crisis discourses. Discourse \& Society, 25(4), pp. 417-423. Available at: https://www.researchgate.net/profile/Ruth_Wodak/publication/274993360_From_Grexit_t o_Grecovery_Eurocrisis_discourses/links/559690e708ae99aa62c81ce8.pdf [Accessed 2 April 2015]. 